\title{
Counterfeiting: Exploring mitigation capabilities and resilience in South African pharmaceutical supply chains
}

\begin{tabular}{|c|c|}
\hline \multicolumn{2}{|c|}{$\begin{array}{l}\text { Authors: } \\
\text { Christine Terblanche }{ }^{1} \text { @ } \\
\text { Wesley Niemann }{ }^{1}\end{array}$} \\
\hline \multicolumn{2}{|c|}{$\begin{array}{l}\text { Affiliations: } \\
{ }^{1} \text { Department of Business } \\
\text { Management, Faculty of } \\
\text { Economic and Management } \\
\text { Sciences, University of } \\
\text { Pretoria, Pretoria, } \\
\text { South Africa }\end{array}$} \\
\hline \multicolumn{2}{|c|}{$\begin{array}{l}\text { Corresponding author: } \\
\text { Wesley Niemann, } \\
\text { wesley.niemann@up.ac.za }\end{array}$} \\
\hline \multicolumn{2}{|c|}{$\begin{array}{l}\text { Dates: } \\
\text { Received: } 01 \text { June } 2021 \\
\text { Accepted: } 04 \text { Oct. } 2021 \\
\text { Published: } 19 \text { Nov. } 2021\end{array}$} \\
\hline \multicolumn{2}{|c|}{$\begin{array}{l}\text { How to cite this article: } \\
\text { Terblanche, C. \& Niemann, W., } \\
\text { 2021, 'Counterfeiting: } \\
\text { Exploring mitigation } \\
\text { capabilities and resilience in } \\
\text { South African pharmaceutical } \\
\text { supply chains', Acta } \\
\text { Commercii } 21(1) \text {, a963. } \\
\text { https://doi.org/10.4102/ } \\
\text { ac.v21i1.963 }\end{array}$} \\
\hline \multicolumn{2}{|c|}{$\begin{array}{l}\text { Copyright: } \\
\text { (C) 2021. The Authors. } \\
\text { Licensee: AOSIS. This work } \\
\text { is licensed under the } \\
\text { Creative Commons } \\
\text { Attribution License. }\end{array}$} \\
\hline \multicolumn{2}{|l|}{ Read online: } \\
\hline 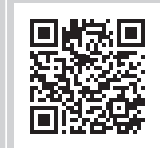 & $\begin{array}{l}\text { Scan this QR } \\
\text { code with your } \\
\text { smart phone or } \\
\text { mobile device } \\
\text { to read online. }\end{array}$ \\
\hline
\end{tabular}

Orientation: Pharmaceutical supply chains (SCs) are experiencing a growing emergence of illicit trade of counterfeited products. This threat is amplified because of global distributed SC networks, increased access to the Internet and challenging economic conditions.

Research purpose: The purpose of this study was to explore risk mitigation capabilities and SC resilience (SCRES) to reduce the effects of counterfeiting in the South African pharmaceutical industry.

Motivation for the study: Developing countries such as South Africa tend to be more vulnerable to counterfeiting, as these countries do not have established responses that are seen in more developed countries, such as SC regulation, track-and-trace technology and enforcement regimes.

Research design, approach and method: This study employed a generic qualitative research design. Semi-structured interviews were used to collect data from 12 pharmaceutical manufacturers, distributors and retailers in the South African pharmaceutical industry. A thematic analysis approach was followed to analyse the collected data.

Main findings: The findings show that the sources of counterfeiting stem from the local and outsourced manufacturing of counterfeited products, presence of unauthorised distributors and importing of counterfeit products. Risk awareness can be enhanced by collaborating with industry members, training members to identify counterfeits and by developing authentication technologies. The industry actively combats counterfeiting by using SCRES enablers including visibility, collaboration, information sharing and by developing an SC risk management culture.

Practical/managerial implications: South African pharmaceutical firms have limited resilience. Therefore, managers should develop flexibility, agility, sensing and redundancy as resilience enables firms to combat counterfeiting.

Contribution/value-add: This study expands the current literature by identifying the unique sources of counterfeiting and risk mitigation capabilities to combat counterfeiting in pharmaceutical firms in a developing country context.

Keywords: supply chain risk mitigation; supply chain resilience; counterfeiting; pharmaceutical firms; qualitative; South Africa.

\section{Introduction}

The trends of outsourcing and use of cost-reducing manufacturing philosophies, such as lean manufacturing, have enhanced efficiency in supply chains (SCs). These trends have also left SCs vulnerable to disruptions and risks (Fiksel et al. 2015:81; Jüttner, Peck \& Christopher 2003:202; Kamalahmadi \& Parast 2016:124; Pettit, Croxton \& Fiksel 2013:61). The first step in designing resilient and efficient SC networks is dependent on an understanding of SC risk sources and the severity of their impact (Lima et al. 2018:124). Counterfeiting is a prominent source of disruption in SCs, especially in pharmaceutical SCs where counterfeits have a direct effect on consumers' health (Lima et al. 2018:117). Upstream, suppliers who are the trademark owners of products being counterfeited, suffer from loss of revenue, deterioration of their brand value and reputation, lost investment and reduced innovation (Thenga 2018). An investigation into the impact of counterfeit medication found that up to $45 \%$ of malaria-related deaths in Africa are associated with the use of counterfeit anti-malarial medication (Renschler et al. 2015:122).

The occurrence of risks such as counterfeiting in the firm's SC calls for coordinated action among all chain members to identify and manage risks to reduce its vulnerability (Fiksel et al. 2015:80-81). 
Supply chain risk management (SCRM) is defined as 'the possibility of an interruption occurring between the demand and supply of a product' (DuHadway, Carnovale \& Hazen 2019:182). Such interruptions originated because of unforeseeable variations in the organisational environment or supply (Craighead et al. 2007:131). To combat the effect of disruptions, firms are taking actions to reduce the adverse effects of disruption in an SC. These actions are known as risk mitigation capabilities which is the ability of the SC to prepare for and recover from a disruption (Craighead et al. 2007:40; Hohenstein et al. 2015:102; Machado, Paiva \& Da Silva 2018:145).

Stevenson and Busby (2015:110-144) proposed countermeasures for improving the resilience of SCs to the counterfeiting threat. This is supported by Machado et al. (2018:139-163) who focused on how firms develop mitigation capabilities and build a resilient SC. To reduce risks and build resilience, SCs have readiness, response and recovery elements in place (Chowdhury \& Quaddus 2016:710). Supply chain resilience (SCRES) is the

[A]bility to support the complex and dynamic nature of modern SCs, by providing solutions to ensure constant and systematic surveillance to vulnerabilities, and to enable agile and flexible responses in any type of disruption. (Fiksel et al. 2015:83; Jüttner \& Maklan 2011:250; Jüttner et al. 2003:200)

Lima et al. (2018:117-135) explored the role of resilience enablers in combatting counterfeits in the pharmaceutical industry. Supply chain resilience stems from enablers such as firms' practices and resources, strategically created to help decision-making processes after disruptions, such as counterfeiting (Kamalahmadi \& Parast 2016:122). These enablers can improve a firm's competitive advantage and aid decision-making processes after a disruption.

\section{Problem statement}

Despite the recent acknowledgement of counterfeiting as an SC risk source (Chaudhry \& Stumpf 2013:189-197; Dégardin, Roggo \& Margot 2014:167-175; Li \& Yi 2017:98-108; Lybecker 2008:389-405; Machado et al. 2018:139-163; Stevenson \& Busby 2015:110-144), only a single study was conducted that explicitly links SCRES elements and risk mitigation capabilities to combat counterfeiting (Stevenson \& Busby 2015:110-144).

Lima et al. (2018:132) call for further empirical studies in vulnerable geographical areas that have not been explored extensively. An issue facing the pharmaceutical industry in South Africa is the influx of counterfeit products (Walsh 2019), with an estimated one in five pharmaceuticals sold believed to be counterfeit (Koffi 2018). Developing countries such as South Africa tend to be more vulnerable to counterfeiting, as these countries do not have established responses that are seen in more developed countries, such as SC regulation, track-and-trace technology and enforcement regimes (Lima et al. 2018:132).
The purpose of this generic qualitative study was to explore risk mitigation capabilities and SC resilience to reduce the effects of counterfeiting in the South African pharmaceutical industry. More specifically, the study aimed to determine the sources of counterfeiting, specific capabilities for combatting counterfeiting in their SCs of the South African pharmaceutical industry. Further, this study explored which SC resilience enablers are used to combat counterfeiting. This study focusses on manufacturing, distribution and retail pharmaceutical firms in South Africa.

The following research questions guided the study:

1. What are the sources of counterfeiting in the South African pharmaceutical industry?

2. Which specific capabilities are used to mitigate against counterfeiting in the South African pharmaceutical industry?

3. Which SCRES enablers are used to combat counterfeiting in the South African pharmaceutical industry?

The contribution of the study is threefold: firstly, the study was undertaken in response to the call of Lima et al. (2018:132) for further empirical studies in vulnerable geographical areas. Secondly, this study expands the current literature by identifying the specific sources of counterfeiting and how firms develop risk mitigation capabilities to combat counterfeiting in pharmaceutical firms in a developing country context. Finally, the study identified the specific SCRES enablers used in the South African pharmaceutical industry.

\section{Literature review}

\section{An overview of the south african pharmaceutical industry}

The South African pharmaceutical industry is governed by the Department of Health (DoH), South African Health Products Regulatory Authority (SAHPRA), South African Pharmacy Council (SAPC), the South African National Accreditation System (SANAS), South African Bureau of Standards (SABS) and the medicines pricing committee. The actors in the pharmaceutical industry are manufacturers, distributors, wholesalers and retail pharmacies (Krebs 2018:2). These actors in the pharmaceutical industry need to be fully aware and understand their obligations and duties under the South African pharmaceutical regulatory authority (Chowles 2017:1). Further, the industry is governed by the single exit price (SEP) that is the maximum price which can be charged, irrespective of volume sold (Krebs 2018:2).

Manufacturers, distributors and retailers may not charge any fee other than the SEP. It should be noted that SEP only applies to medicines that can only be obtained from a pharmacy. Products that can be bought at a supermarket, such as paracetamol, are not subject to the SEP. There are maximum allowable price increases set by the Minister of Health on an annual basis (Chowles 2017:1). The South African pharmaceutical market is therefore vulnerable to the risk of counterfeiting. South Africa has a large number of 
land and seaports which make it difficult to monitor the entry points effectively. This implies that counterfeit pharmaceuticals can enter South Africa from multiple entry points, therefore making illegal importation into the country much easier (Von Holdt 2017:2).

\section{Counterfeiting in the pharmaceutical supply chain}

Counterfeiting is the act of intentionally and illegally producing, or mislabelling a product regarding its identity and source to appear to customers as a genuine product. Counterfeit pharmaceuticals may apply to both branded and generic products (Machado et al. 2018:151). Pharmaceutical SCs have experienced an increase in illicit trade, because of the increased attractiveness of the Internet, challenging economic conditions and global and dispersed networks (Li \& Yi 2017:102; Lybecker 2008:393). This has also led to fragmented information, which is further exacerbated by the high number of intermediaries and a low degree of collaboration (Taylor 2014:132).

Three possible generic upstream sources of counterfeiting exist (Machado et al. 2018:157; Stevenson \& Busby 2015:111-112). The first is national production, essentially, products manufactured in the domestic market. This can result from outsourcing manufacturing to non-reputable manufactures. These non-reputable manufacturers illegally manufacture additional quantities and sell them via an unauthorised channel (Stevenson \& Busby 2015:111-112). The second source is imported products or fake items that enter via a country's ports and borders (Machado et al. 2018:157; Mohamed 2012:8). The third source of counterfeiting relates to independent manufacturers who produce counterfeit products (Machado et al. 2018:157). The sources of counterfeiting in the downstream chain relate to unauthorised distributors; these are importers who receive and distribute counterfeit products via an unauthorised retail channel (DiMase et al. 2016:1837; Machado et al. 2018:158). A common source of counterfeit medication in the South African pharmaceutical SC is medication that failed quality tests. These medicines fell into the hands of corrupt individuals before being destroyed who sells the medicines to unsuspecting parties (Antonie et al. 2018:2).

\section{Mitigation capabilities to combat counterfeiting}

Firms develop risk mitigation capabilities to enable them to prepare for and reduce the effects of risks (Ambulkar, Blackhurst \& Cantor 2016:1400). Firms can use risk mitigation as a systematic reduction in the extent of exposure to risk and the likelihood of its occurrence. Risk mitigation capabilities can be grouped into two categories. Firstly, intra-firm risk mitigation capabilities applied only inside the firm. Secondly, inter-firm risk mitigation capabilities require coordination among SC links.

\section{Intra-firm risk mitigation capabilities}

Firms can mitigate counterfeit risks by developing research and development (R\&D) strategies to improve products or processes (Wilson, Grammich \& Chan 2016:352). Furthermore, a firm can decrease pricing strategies to ensure attractive pricing to retain customers for legitimate products, as counterfeit products tend to be less expensive than original products (Cesareo \& Stöttinger 2015:531; Stumpf \& Chaudhry 2010:309). In addition, firms can appoint internal teams to monitor whether partners act in accordance with the established agreement to improve brand protection or to study counterfeiter activities and perform initial investigations (Meraviglia 2015:235; Wilson et al. 2016:253).

\section{Inter-firm risk mitigation capabilities}

By developing laws and regulatory bodies, countries will be able to effectively monitor and prosecute counterfeiters (Hoecht \& Trott 2014:107; Lima et al. 2018:124). There should be cooperation among national and international entities to combat counterfeiting (Hoecht \& Trott 2014:108). The constant monitoring of SC members can reduce a firm's vulnerability. This can be achieved by establishing a system of supervision and audits of SC members (Blackhurst, Dunn \& Craighead 2011:380). This will enhance a firm's ability to anticipate and react to disruptions (Cho, Fang \& Tayur 2015:281). Furthermore, firms should build relationships with their SC partners to ensure collaboration and information sharing. This will enhance SC visibility and keep tight control of the channels that products go through until it reaches the end customer.

Raising risk awareness among stakeholders is one of the most challenging risk mitigation capabilities to implement (Meraviglia 2015:240-241). Employees and customers should be trained to identify counterfeit products. Training will involve continuous communication about how to identify possible counterfeit products, such as labelling, packaging and the authorised retailers (Chaudhry \& Stumpf 2013:192; Hoecht \& Trott 2014:104). Firms should enhance risk awareness by informing their employees about risks associated with counterfeits in SCs (Stumpf \& Chaudhry 2010:308, Wilson et al. 2016:356). Firms should increase risk awareness among employees, SC partners and consumers (Lima et al. 2018:124).

Technologies to combat counterfeiting enable firms to identify, authenticate and track products (Li 2013:172). Authentication technologies can be divided into two categories. The first category is relatively inexpensive and easy to identify (Kwok et al. 2010:1022; Li 2013:173). These are technologies that are visible to the human eye such as watermarks, unique packaging and expiry dates (Kwok et al. 2010:1023). However, it should be noted that these technologies are easier to falsify. Further, these technologies can drive up the costs of the firm, as they require training of employees and customers (Wilson et al. 2016:356). The second category is technologies that are harder to identify and tend to be more expensive; however, they are harder to copy (Kwok et al. 2010:1022; Li 2013:174). These technologies require distinct reading devices for authentication, and these include serialisation, digital watermarks and chemical 
fingerprints ( $\mathrm{Li} 2013: 174)$. Traceability is essential in ensuring SC safety, as it allows for real-time information, which enhances risk-informed decision-making, increased control during reverse logistics, faster inspection operations and rapid identification and reports of suspected counterfeited products (Enyinda \& Tolliver 2009:227; Kumar, Dieveney \& Dieveney 2009:194; Kwok et al. 2010:1025; Urciuoli 2010:19).

To enable a firm to analyse all the information gathered during traceability, big data and analytics solutions should be implemented. These solutions can be used as a tool to detect counterfeiting (Kwok et al. 2010:1024). Big data and analytics solutions can be used to indicate possible occurrences of counterfeiting by analysing changes in SC flow patterns (Papadopoulos et al. 2016:1113). Another way to explore risk mitigation capabilities to fight against counterfeits is to see each incident of counterfeiting as an SC disruption. Therefore, SCRES may be an effective way to prevent and combat counterfeits (Kamalahmadi \& Parast 2016:120; Sheffi \& Rice 2005:44).

\section{Supply chain resilience enablers}

Supply chain resilience represents an SC's capability to react to changes and disruptions in business operations (Kamalahmadi \& Parast 2016:122; Ponomarov \& Holcomb 2009:131). The more resilient the SC, the better the response to disturbances (Sheffi \& Rice 2005:44). Resilience enablers allow firms to get ready and adjust to respond positively to disruptions (Kamalahmadi \& Parast 2016:122).

Re-engineering as an enabler involves redesigning the SC to reduce risk exposure, build resilience and overcome SC disruption (Scholten, Scott \& Fynes 2014:220). Firms can combat against counterfeiting by evaluating existing sourcing criteria or design decisions (efficiency vs redundancy) from an SCRES perspective that may mitigate vulnerabilities (Christopher \& Peck 2004:8; Kamalahmadi \& Parast 2016:125). As the pharmaceutical industry is characterised by a high number of intermediates, there is an increased vulnerability to disruptions in the SC such as counterfeiting (Enyinda \& Tolliver 2009:227).

Visibility is the ability to reduce information asymmetry, quickly identify disruptions, to implement changes effectively and enable real-time monitoring through SC transparency (Christopher \& Peck 2004:8; Ehrenhuber et al. 2015:7). Supply chain transparency can be achieved through early warning communication, information sharing, database and predictive capacity (Tukamuhabwa et al. 2015:5610). Visibility enables firms to monitor important behaviours to enhance threat awareness and better prepare for disturbances (Rashid et al. 2014:290; Tukamuhabwa et al. 2015:5617). The development of traceability systems helps to protect consumers, prevent and respond to adversarial disruptions (Coustasse, Arvidson \& Rutsohn 2010:110; Enyinda \& Tolliver 2009:225; Speier et al. 2011:731; Taylor 2014:141).

\section{Collaboration is the:}

$[A]$ bility to join efforts and work effectively within a firm or with other SC entities for mutual benefit. In the context of SCRES, it reinforces the importance of internal and external communication, knowledge sharing including the ability to cooperate and join forces with international firms and government agencies. (Scholten et al. 2014:221)

Firms may engage with their customers by encouraging them to actively report suspected products, inquiring about the product's authenticity or asking about purchases from authorised sellers (Cesareo \& Stöttinger 2015:532).

An SCRM culture can be achieved by instilling an ethos of resilience and risk consciousness and to make it the concern of everyone (Christopher \& Peck 2004:9; Ehrenhuber et al. 2015:8; Pettit et al. 2013:60). The implementation of an SCRM culture may help to mitigate specific susceptibilities, such as counterfeiting. From the consumer's point of view, the general awareness of counterfeit risk is supported by fostering an SCRM culture (Cesareo \& Stöttinger 2015:531), as direct engagement with them may help them to learn more about counterfeits (Cho et al. 2015:284; Hoecht \& Trott 2014:109).

Redundancy as an enabler is the 'replication of addition of capacity and/or resources that can be invoked during a disturbance to replace the loss of capacity and/or resources during a disturbance' (Soni et al. 2015:192). This can be achieved by adding additional suppliers to act as shockabsorbers during a disruption. Redundancy is identified as a possible route to flexibility. Flexibility is being able to foresee threats and react instantly (Rashid et al. 2014:290).

Information sharing as an enabler of SCRES refers to the exchange of data and proprietary information among internal and external SC members (Lima et al. 2018:126). The sharing of information, including communication and coordination among all partners in the SC, is important recover from an adverse event (Dekker, Sakaguchi \& Kawai 2013:131; Kamalahmadi \& Parast 2016:125). In addition, by increasing the visibility of demand information across the SC, risk is reduced. The information that an organisation shares with its SC partners is among the most critical of its assets (Kamalahmadi \& Parast 2016:125).

Agility is the ability to thrive in a continuously changing, unpredictable business environment; therefore, firms affected by risks and disruptions, such as counterfeiting, should implement quick SC redesign to reduce the impact of disruptions and facilitate recovery. Firms can respond to the risk of counterfeiting by building agility into their SC through synchronisation of activities through shared information, seeking to reduce complexity and postpone the final assembly and distribution of products, managing processes not just functions and by utilising appropriate performance metrics (Christopher 2016:120; Pettit et al. 2013:60).

Control and trust are both enablers that protect against the entrance of counterfeited products on both sides of the SC 
(Dekker et al. 2013:131; Kamalahmadi \& Parast 2016:125). It is easier for a firm to notify and negotiate with a supplier who committed a violation than to terminate the contract with them and then have to find a new supplier (Lima et al. 2018:130; Machado et al. 2018:152; Stevenson \& Busby 2015:130). Further, control and trust increase a firm's capacity to become resilient to counterfeiting. Trust can be built, and control can be implemented by certification of suppliers, contracts, sporadic visits to manufacturing suppliers and distributors, creating a strict selection criterion for suppliers and distributors as well as inventory inspection (Machado et al. 2018:152-154; Naderpajouh et al. 2015:8).

\section{Methodology \\ Research design}

The study used a generic qualitative research design. The objective of generic qualitative research is to discover various viewpoints surrounding a specified topic to create a detailed understanding and description of a specific phenomenon (Plano-Clark \& Creswell 2014:289). This study endeavoured to create an in-depth understanding of risk mitigation capabilities and SCRES enablers employed by manufacturing, distribution and retail pharmaceutical firms in South Africa to combat counterfeiting. Generic qualitative studies involve semi-structured interviews with multiple participants who are selected through purposive-sampling strategies (Merriam 2009:23-24).

\section{Sampling}

The unit of analysis for this study was pharmaceutical manufacturers, distributors and retailers in South Africa. The sample consists of 12 firms that allowed for a total of 12 semistructured interviews. Seven pharmaceutical manufacturers, three pharmaceutical distributors and two pharmaceutical retailers were included in the sample. A larger number of pharmaceutical manufacturers were interviewed as the counterfeiting problem tends to occur upstream. The final sample size was grounded in the principle of data saturation (Guest, Bunce \& Johnson 2006:74). In this study, the majority of the codes were identified after the sixth interview and the main themes were established. The remaining interviews did not offer any new noteworthy data. Details of the participants are presented in Table 1.

The study used homogenous sampling, a form of purposive sampling, to select firms that have similar characteristics (Creswell 2012:518). This ensured that diverse and valuable information could be obtained on risk mitigation capabilities and SC resilience enablers used by pharmaceutical firms to combat counterfeiting. These pharmaceutical firms needed to be actively combatting counterfeiting. To select individual participants, homogenous and snowball sampling were used (Polit \& Beck 2012:518). The following characteristics were used to select the participants: (1) participants had to be employed at the selected pharmaceutical firms; (2) participants had to be in a middle-to-senior management position and (3) the participant had to be involved in the firm's SCRM practices. Once data collection began, the
TABLE 1: Profile of the study participants.

\begin{tabular}{llcc}
\hline Pseudonym & Position & Firm & $\begin{array}{c}\text { Length of } \\
\text { interview (min) }\end{array}$ \\
\hline P1 & Managing director and responsible pharmacist & F1 & 25 \\
P2 & Logistics specialist & F2 & 15 \\
P3 & Head of planning and operations & F3 & 25 \\
P4 & Operations manager & F4 & 30 \\
P5 & Zone security director & F5 & 60 \\
P6 & Head of supply chain & F6 & 42 \\
P7 & Distribution manager & F7 & 25 \\
P8 & Regional security head and compliance manager & F8 & 45 \\
P9 & Group legal affairs manager & F9 & 40 \\
P10 & Forensics manager & F10 & 20 \\
P11 & National risk manager & F11 & 15 \\
P12 & Responsible pharmacist & F12 & 15 \\
\hline
\end{tabular}

Note: Average duration $=30 \mathrm{~min}$.

researchers used snowball sampling by asking participants to recommend another potential participant who would meet the inclusion criteria of the study (Quinlan et al. 2015:181).

\section{Data collection}

Data were collected using 12 semi-structured face-to-face interviews, one per participating firm. Semi-structured interviews are most suitable where the researcher wants to collect information on people's experiences and opinions in a specific environment (Rowley 2012:262). Detailed insights were obtained from participants by asking open-ended questions. Before commencing with data collection, a pretest was conducted with one practitioner to assess the appropriateness of the interview questions. Minor changes were made to the discussion guide to improve the flow of the interview. Participants were given assurances of anonymity and confidentiality and were also requested to read and sign an informed consent form.

\section{Data analysis}

Thematic analysis was used to analyse the collected data. ATLAS.ti version 8 was used to guide the thematic analysis approach. ATLAS.ti is a sophisticated software programme that systematically analyse complex phenomena hidden in unstructured qualitative data. An exploratory analysis was conducted by listening to the audio-recordings, while reading the transcribed interviews to familiarise the researchers with the data and to create preliminary inductive codes (Creswell 2012:243). These inductive codes were combined with a priori codes identified from the literature and a master code list was drawn up. Relevant segments of text from the transcriptions were then coded and then refined after patterns of themes were identified, which provided meaning to the data (Braun \& Clarke 2012:63-65).

\section{Trustworthiness}

Various techniques were employed to ensure the trustworthiness of this study, more specifically credibility, dependability, transferability and confirmability (Polit \& 
Beck 2012:584). Credibility was ensured by making the participants feel at ease so that they were forthcoming, and all their responses were truthful (Shenton 2004:67). Before every interview, participants were reminded that their responses and participation were confidential and that they could decline to answer any question they did not feel comfortable with. Dependability was ensured by creating a comprehensive record of the method used for implementation and the research design (Shenton 2004:72). Transferability was ensured through a comprehensive description of the context of the study, the various participants, their job designation and gender, as well as the length of the interviews with each participant (Shenton 2004:70). Confirmability was established by using open-ended and the appropriate probing questions during interviews and producing accurate, word-for-word transcriptions of all interviews (Milne \& Oberle 2005:415-416).

\section{Ethical considerations}

Ethical clearance was obtained from the University of Pretoria, Faculty of Economic and Management Sciences Research Ethics Committee, reference number: 15107 932/2019. Each participant was required to read and sign an informed consent form before the start of the interview. The form accentuated that participation in the study was voluntary and that the participant could withdraw at any time, and provided assurances of anonymity and confidentiality. The latter requirement was achieved by using pseudonyms and removing any reference to the names of individuals and firms in the transcripts and the final presentation of the data.

\section{Findings}

This study identified three main themes related to the study's research questions. These themes are related to the following: the sources of counterfeiting, the risk mitigation capabilities employed to combat counterfeiting and resilience enablers employed to combat counterfeiting. These themes and their related sub-themes are discussed in this section, complemented by quotations from the data and linkages to the relevant literature. Table 2 contains a summary of the themes and subthemes.

\section{Sources of counterfeiting}

The first theme links back to research question 1 as it considers the sources of counterfeiting for the South African pharmaceutical industry. This theme involves two subthemes: upstream sources of counterfeiting and downstream sources of counterfeiting.

\section{Upstream sources of counterfeiting}

Upstream sources of counterfeiting relate to sources of counterfeiting that originate on the supply side of the value chain (Machado et al. 2018:157). Five participants indicated local manufacturing for the informal market as a source of counterfeiting. This includes products being produced in the South African market to be sold in the informal
TABLE 2: A summary of the research themes.

\begin{tabular}{|c|c|c|}
\hline Main themes & Sub-themes & Elements \\
\hline $\begin{array}{l}\text { Sources of } \\
\text { counterfeiting }\end{array}$ & $\begin{array}{l}\text { Upstream } \\
\text { sources } \\
\text { Downstream } \\
\text { sources }\end{array}$ & $\begin{array}{l}\text { - Local manufacturing for the informal market } \\
\text { - Outsourced manufacturing and distribution } \\
\text { - Unauthorised distributors } \\
\text { - Diversion } \\
\text { - Imported counterfeits } \\
\text { - Non-reputable pharmacists or doctors } \\
\text { - Internet sales } \\
\text { - Lack of accessibility to doctors and pharmacists } \\
\text { - Lack of affordability of pharmaceutical products }\end{array}$ \\
\hline $\begin{array}{l}\text { Risk mitigation } \\
\text { capabilities to } \\
\text { combat } \\
\text { counterfeiting }\end{array}$ & $\begin{array}{l}\text { Intra-firm risk } \\
\text { mitigation } \\
\text { capabilities } \\
\text { Inter-firm risk } \\
\text { mitigation } \\
\text { capabilities }\end{array}$ & $\begin{array}{l}\text { - Pricing strategies } \\
\text { - R\&D strategies } \\
\text { - Developing an internal structure } \\
\text { - Strict government laws and regulations } \\
\text { - Enhancing national cooperation } \\
\text { - Monitoring supply chain members } \\
\text { - Enhancing risk awareness } \\
\text { - Training members to identify counterfeits } \\
\text { - Enhancing brand image } \\
\text { - Authentication technologies } \\
\text { - Traceability } \\
\text { - Big data and analytics }\end{array}$ \\
\hline \multirow[t]{2}{*}{$\begin{array}{l}\text { Supply chain } \\
\text { resilience } \\
\text { enablers to } \\
\text { combat } \\
\text { counterfeiting }\end{array}$} & $\begin{array}{l}\text { Visibility } \\
\text { Collaboration } \\
\text { Supply chain risk } \\
\text { management } \\
\text { culture }\end{array}$ & \\
\hline & $\begin{array}{l}\text { Information } \\
\text { sharing }\end{array}$ & \\
\hline
\end{tabular}

$R \& D$, research and development.

market. These products are sold at a lower price than the pharmaceuticals sold in the legal SC. Refer to the exemplary quotation below:

'I learnt today they are counterfeiting drugs in South Africa where they are manufacturing it in the townships.' (P3, male, head of planning and operations)

Moreover, three participants identified outsourced manufacturing and distribution as a source of pharmaceutical counterfeiting. This source exists because of the possibility of these products being swopped for counterfeits at the source of production in a foreign country. Further, these products can be stolen while in transit from the source of production to the port. This can be seen from the following quotations:

\footnotetext{
'...it can be that someone on the way the port when you outsource distribution that the products are stolen and resold in another market. I mean its real issues that happens so ja.' (P2, male, logistics specialist)

'So there's a couple of things so let's say you get the factory and you got the harbour, I've heard of cases ... where it leaves and the factory when it comes to the port, the containers already been so swapped for ones with counterfeit drugs. So, your first risk of counterfeit drugs is from the factory to the port ....' (P3, male, head of planning and operations)
}

\section{Downstream sources of counterfeiting}

Downstream sources of counterfeiting related to sources on the distribution side (Machado et al. 2018:157). Five participants identified unauthorised distributors as a source of counterfeiting. This includes distributors who are 
not registered with the DoH and SAHPRA. Unauthorised distributors further involve products that were stolen while in transit, or failed tests that should have been destroyed. Instead, these products then ended up in the hands of unscrupulous people and sold to unsuspecting parties at lower prices. This is clear from the quotations below:

'Should we buy from non-reputable companies that can be counterfeit.' (P1, male, managing director and responsible pharmacist)

'If I should buy from a distributor who is not registered, I mean that could be a source of counterfeited products.' (P12, female, responsible pharmacist)

An additional source of counterfeiting is diversion, which is also known as parallel import. Diversion includes legitimate products that were meant for one market that end up in another market. Six participants described how these products were obtained through unauthorised distributors who buy these products in one country and then re-sell these products, typically at lower prices, in the local market. The quotation below illustrates this point saliently:

\begin{abstract}
'...basically, is what we call suitcase purchase diversion. So, someone actually jumps up to a plane, goes into, um, let's pick your country. Pakistan, two or three suitcases. He actually goes into a distributor. He buys kind of products at a, at a lower price, probably close to expiry date. He fills the suitcases, travels back into the country and then basically market's a product in the open market at a premium. So, we kind of seen a lot of product basically coming into the country through what we see suitcase purchase diversion.' (P8, male, regional security head and compliance manager)
\end{abstract}

Additionally, imports of counterfeit products that enter a country through its ports and borders were identified as a source of counterfeiting. Eight participants identified imports of counterfeit pharmaceuticals as a source of counterfeiting in the South African pharmaceutical industry. See the supporting quotations below:

'Most of falsified medicines today are coming from abroad. Okay. And the main or origin is China and India. Right. So, this, I think it represents something like more than $90 \%$ of falsified medicine that is seized worldwide. I mean from Asia and are coming from China mainly. And India.' (P5, male, zone security director)

'Most products that are a risk of being counterfeit will most likely be imported from India or China. I mean that is the most talked-about sources.' (P11, male, national risk manager)

Another source of counterfeiting that was identified by three participants is non-reputable pharmacies or doctors. This involves pharmacists or doctors buying a less expensive product from a non-reputable distributor or agents. These products are more likely to be counterfeit and sold to unsuspecting parties. The quotations below clearly illustrate this point:

'If you get counterfeit medicine that's because pharmacies send back stock for credit and they round trip the stock then they send you a counterfeit medicine. Independent pharmacy, a skelm pharmacy that sent it back.' (P1, male, managing director and responsible pharmacist)

'And where the counterfeit product can come in is if the doctor gets a cheaper product from a street sale, rather than the original product he can buy with me. If he does, it's a risk.' (P4, male, operation manager - translated from Afrikaans)

An emerging source of counterfeit products is Internet sales. The products sold online by unauthorised distributors tend to be less expensive. Four participants identified this as a source of counterfeiting. This is supported by the following quotation:

'The next risk is people purchasing products on internet because you can find everything and most of the time without asking your prescription, you know what, we can see that a $50 \%$ of the product that is purchased on internet is falsified.' (P5, male, zone security director)

As noted by three participants, some consumers do not have access to doctors or pharmacies. Further, these consumers cannot afford doctors' consultations for prescriptions or to buy legitimate products from registered pharmacies. Thus, they resort to buying less expensive products on the street, and these products tend to be counterfeited. This is supported by the following quotation:

'I mean these vaccines are expensive so obviously if someone who does not have access to a doctor, pharmacy or the money to buy this and he can get it cheaper online, and online sales of counterfeits is becoming a real issue for us these products get sold on the web, the dark web and even social media like Facebook. Anyway, so these people don't have the money or accessibility so they will buy these products...' (P2, male, logistics specialist)

The findings confirm those of Machado et al. (2018:157), indicating that sources of counterfeiting are local manufacturing of counterfeited products, unauthorised distributors and imports of counterfeit products. Additionally, the findings identified sources of pharmaceutical counterfeiting that have not been identified in the literature. These sources are outsourced manufacturing and distribution, diversion, nonreputable doctors or pharmacies and Internet sales, lack of accessibility to doctors or pharmacists and lack of affordability of pharmaceutical products.

\section{Risk mitigation capabilities to combat counterfeiting}

Risk mitigation capabilities to combat counterfeiting links back to research question 2 as it identifies the specific risk mitigation capabilities employed in the South African pharmaceutical industry. This theme involves two subthemes: intra-firm risk mitigation capabilities and inter-firm risk mitigation capabilities.

\section{Intra-firm risk mitigation capabilities}

One participant indicated that the South African pharmaceutical industry is governed by the SEP. The SEP applies to all pharmaceutical products that can be purchased 
with a prescription. Therefore, firms in the South African pharmaceutical industry cannot change the prices of these products to combat counterfeiting. Refer to the exemplary quotation below:

'The SEP is the price at which a manufacturer must sell to all pharmacies, irrespective of volume sold. The introduction of the transparent pricing ensured that no-one could supply medicine according to a bonus system, rebate system or any other incentives. It should be noted that SEP applies to medicines which can only be bought in a pharmacy; medicines such as paracetamol, which you can buy in a supermarket, are not subject to SEP.' (P2, male, logistics specialist)

As indicated by three participants, products that are not governed by the SEP such as over the counter products (OTCs), increasing or decreasing the price will have no effect on combatting counterfeiting, as these products are easy to come by and counterfeit. This can be seen from the following quotation:

'Then you have your non-prescription drugs, OTCs. We're finding in the South African context OTCs are more targeted by counterfeiters. Because there is already a market for it. You have to go see your doctor to get a prescription.' (P8, male, regional security head and compliance manager)

Pharmaceutical firms can combat counterfeiting by developing R\&D strategies such as improving infrastructure, products and processes. As indicated by five participants, their firms use unique packaging and labelling to combat counterfeiting, such as tamper-proof labels on packaging. This is clear from the quotations below:

'We have a tamper evidence labels. So that, you know, if you're a patient, you receive one of our products. And you'll see that the seal is broken on the box, then you know that the box has been tampered with...' (P7, male, distribution manager)

'We have our own research and development laboratory, which is WHO and FDA approved which is who we give the approved when we do the analysis and this and stuff like that as well.' (P9, male, group legal affairs manager)

Developing an internal structure, which contains teams who analyse possible counterfeit activities and perform initial investigations, will assist pharmaceutical firms in combatting counterfeiting (Meraviglia 2015:233; Wilson et al. 2016:353). Six participants indicated that their firms formed pharmacovigilance departments to analyse counterfeit activity that deals with tip-offs and perform initial investigations. The quotation below illustrates this point saliently:

'There's no specific training but like all companies, like pharmaceutical companies got a pharmacovigilance department that deals with these types of things. Cause normally you'll get a customer complaint that the product's not working, and we will normally get products, we'll test it or there's something. So, any customer complaint about a product referred through to our pharmacovigilance department where we do analysis with tests and things like that.' (P9, male, group legal affairs manager)

The literature found that the use of pricing strategies and increasing or decreasing prices by firms can combat counterfeiting (Lybecker 2008:394; Stumpf \& Chaundry 2010:308). However, the findings of this study contradict this, as the South African pharmaceutical industry is governed by the SEP. Pharmaceutical firms can combat counterfeiting by developing $R \& D$ strategies such as improving infrastructure, products and processes (Green \& Smith 2002:94; Wilson et al. 2016:352).

\section{Inter-firm risk mitigation capabilities}

Three participants indicated that the South African government's law and regulations are effective in combatting counterfeiting, with the DoH and SAHPRA. See the supporting quotation below:

'We ensure the products that we stock and distribute is licensed by the manufacturer, registered and approved by SAHPRA. So, there is a whole process. So, the whole industry is completely over-regulated.' (P4, male, operations manager - translated from Afrikaans)

The findings of this study indicate that by developing practices to enable collaboration among national and international entities, government, regulatory authorities and police can assist firms in combatting counterfeiting. As indicated by seven participants, Interpol, World Customs Organization, the South African Police Service (SAPS), SAHPRA and DoH have been working together to combat pharmaceutical counterfeiting in South Africa. The development of the pharmaceutical crime task team has enabled further collaboration between the above-mentioned entities to address the counterfeiting issue in South Africa. The quotation below clearly illustrates this point:

'We...got a pharmaceutical crime task group where we also have various manufacturers and distributors when we discuss problems in a quarterly basis. Also, at that meeting, we have the Hawks, we have Interpol, we have, CIPC, we have SAHPRA, their representatives from various agencies where we have in quarterly discussions... they got a committee, which involved now dealing with counterfeiting and theft the products..' (P9, male, group legal affairs manager)

Six participants indicated that the monitoring systems of firms in the South African pharmaceutical industry focus on the identification of members who sell counterfeits, the confiscation of the products and the prosecution of counterfeiters. They are constantly monitoring their SC members through audits and monitoring the external environment through social media, the web and dark web. Refer to the exemplary quotations below:

'I think it's through investigating the manufacturers and looking you know and have they had any issues before are the FDA approved of the GMP compliant looking at their processes so you physically got a visit and say okay now walk us through your process so when you hand over that shipment of drugs from the backdoor of your factory how sure are you gonna be that that thing is going to remain sealed and get onto the ship so you have to audit those processes so we will we can audit all of that.' (P3, male, head of planning and operations) 
'We have a very efficient search engine that we browse in the dark web and in the web and find ... where the products coming from.' (P5, male, zone security director)

Five participants indicated that there is an increase in risk awareness involving counterfeit pharmaceuticals in South Africa. Firms are implementing standards operating procedures (SOPS) when training personnel, and this training includes making employees aware of the counterfeit threat. The development of the pharmaceutical crime task team has been raising awareness among all industry members and law enforcement of the counterfeiting threat. This can be seen from the following quotation:

'They start with the doctors and then they start with the pharmacies who actually you are selling or dispensing the product and then the pharmacist can actually make the patient aware this is what's going.' (P6, female, head of supply chain)

All participants indicated that all members of the industry are aware of who the authorised manufacturers, distributors and retailers are, as SAHPRA listed all these members on their website. Firms use unique product packaging and labelling such as data matrix codes on their boxes. Firms also have SOPS for training employees, and this training includes training members on how to identify counterfeits. Moreover, three participants indicated that they are involved in training industry members from SAPS, Interpol, SAHPRA and customs to identify counterfeits. This is clear from the quotations below:

'...we have our SOPS for training our employees. We train them on how to handle these products and how to identify authentic products and counterfeit ones and how to report it. Everyone receives this training no matter of their position....' (P2, male, logistics specialist)

'I work closely with SAHPRA representatives as well. The law enforcement unit. As a matter of fact, three years, four years ago I had the whole law enforcement unit trained at our expense. We appointed a person to train them on GMP. The process products go through manufacturing from procurement... So, we work closely with the authorities. So, we give a hundred percent cooperation.' (P9, male, group legal affairs manager)

Four participants indicated that firms are creating awareness across the African continent of counterfeit medication and its adverse effects, thus enhancing their brand awareness through sponsorships and customer care hotlines. This diminishes the counterfeiters' urge to imitate their products. The quotation below illustrates this point saliently:

'So, it's just, you know, for people to get a visual approach on, on what is the main issue there. We are working now, we do for a new initiative in western Africa, we have an editor for the unit, these kids a book where we are getting some message there about the risk or the threat for of falsified medicine.' (P5, male, zone security director)

Seven participants mentioned that firms develop technologies to verify original products and detect counterfeits. These technologies are difficult to duplicate. Findings indicate that firms test all products that are outsourced for manufacturing through forensic laboratory testing and have more visible authentication technologies like tamper-proof seals on the packaging. See the supporting quotations below:

'So it often happens closer to the manufacturing end and those drugs come in sometimes ok that drug then comes in is then counterfeit but because we send all the drugs to for lab testing will discover there something wrong with it and then either we send it for destruction, we send more samples back to India for testing if find the same thing we have to destruct.' (P3, male, head of planning and operations)

'a customer service hotline so basically on the SKU you have the batch number expiry and then there's a code that printed as well as specific code and if you want to verify that the park is authentic pack you can dial the number and you give them the specific code and if that code is not available or if a company does not have the code on system then you know that's a counterfeit product.' (P6, female, head of supply chain)

All participants confirmed the usage of batch tracking, and this enables a firm to track a batch, but not an individual product. However, all firms are moving towards serialisation, and this will enable firms to track an individual product from the point of manufacturing to the end-consumer. All firms in the South African pharmaceutical industry need to implement serialisation by June 2022. This will enable pharmaceutical firms to effectively combat counterfeiting. The quotation below clearly illustrates this point:

'The technology in South Africa is still not good enough for us to track an individual product, we track batches. If ... So, it's still a problem in South Africa, we are working with barcodes, we do not work with 3D barcodes [serialisation]. And we will now for the first time now in December kicks it off that a manufacturer will provide a QR code. on a product, we can scan the code and will now be able to track exactly where that specific unit is.' ( $\mathrm{P} 4$, male, operations manager - translated from Afrikaans)

Only a single participant indicated that their firm uses big data and analytics in the form of information obtained from their traceability efforts to determine the sources of counterfeiting and identify markets that are vulnerable to counterfeiting. This is supported by the following quotation:

'You can get a batch number, lot number or batch number or expiry date. We can through data analytics pinpoint exactly globally where that product was manufactured, which port it was shipped through and which port of destination, what logistics and distribution capabilities were used to get the product into the warehouses or to the end customer we will be able to pinpoint that entire value chain. So yes, I think data analytics is an important aspect and, of course, in terms of our fight against counterfeiting. If you also look at product integrity you can through data analytics say which product markets are more prone to counterfeiting so we can differentiate between various markets where we have problems and where we don't have problems.' (P8, male, regional security head and compliance manager)

This study confirms the findings of Lima et al. (2018:121-122), indicating that by developing R\&D strategies and internal structure firms can combat counterfeiting (Stumpf \& Chaundry 2010:308; Wilson et al. 2016:352). Through strict 
government law and regulations, collaborating with industry members, creating partner strategies, constant monitoring of SC members, raising risk awareness, training members to identify counterfeits, strengthening their brand image, developing authentication technologies and traceability will enable firms to combat counterfeiting (Chaudhry \& Stumpf 2013:192; Coustasse et al. 2010:111; Hoecht \& Trott 2014:107; Kwok et al. 2010:1022; Lybecker 2008:392; Stevenson \& Busby 2015:120; Urciuoli 2010:16).

\section{Resilience enablers to combat counterfeiting}

Resilience enablers to combat counterfeiting links back to research question 3 as it identifies resilience enablers employed by the South African pharmaceutical industry to combat counterfeiting.

Eleven participants indicated that there is currently limited visibility in the South African pharmaceutical industry because of the use of batch tracking. Batch tracking does not enable firms to track individual products throughout the SC. However, the shift to serialisation in the South African pharmaceutical industry will increase the visibility of the pharmaceuticalSC. Additionally, theincrease in transparency, accountability and responsibility enabled by visibility inhibits illegal behaviour because it is easier to link it back to the firm. Moreover, visibility promotes collaboration by sharing sensitive information among SC agents. See the supporting quotation below:

'We are currently using batch tracking, but we are in the process of implementing serialisation, which is a coding system that will help us track individual products from the point of manufacture to the end consumer. This will give us full visibility.' (P11, male, national risk manager)

As indicated by seven participants, firms can assist the government to identify and seize counterfeits by developing internal teams to provide information and report incidents. Collaboration is considered to increase pharmaceutical SC costs for counterfeiters, by establishing licences or certifications to their distributors so that local pharmacists would not collaborate with counterfeiters. The quotation below clearly illustrates this point:

'We ensure the products that we stock and distribute is licensed by the manufacturer, registered and approved by SAHPRA... we need to ensure that when a manufacturer comes to us to distribute his products, we need its registration and get his documentation to say that he may sell his products to us, that list of products has to be checked against the list of the $\mathrm{DoH}$... to ensure that those are also in line. So, we are so limited in terms of the products we can store and distribute. For us to buy a counterfeit product from the street or from a manufacturer not registered is not who is not licensed the products it manufactured registered or licensed.' (P4, male, operations manager - translated from Afrikaans)

Five participants indicated that a risk management culture enhances awareness of risks, such as counterfeiting. Further, direct communication with customers reduces vulnerability through enhancing brand reputation. This is supported by the following quotation:

'...advocacy and awareness is key and basically through our pharmacovigilance as well. So basically, it's uh, doctors, patients basically, uh, the various areas that handles our product when it comes to counterfeiting, ... And so, the more patient advocacy and external advocacy the easier it is to mitigate the problem of counterfeiting.' (P8, male, regional security head and compliance manager)

Information sharing within and among firms tends to increase risk awareness as indicated by five participants. These firms can engage with customers by establishing communication channels to share information pertaining to counterfeiting risk. This enables the reporting of suspected products, customer inquiries about the product's authenticity or purchases from authorised sellers. Refer to the exemplary quotations below:

'a customer service hotline so basically on the SKU you have the batch number expiry and then there's a code that printed as well as specific code and if you want to verify that the pack is authentic pack you can dial the number and you give them the specific code and if that code is not available or if a company does not have the code on system then you know that's a counterfeit product.' (P6, female, head of supply chain)

'We collaborate with our supplier, our distribution agent. They in term belong to a body, you know, that that meets on a regular basis, you know, with other pharma manufacturers and also other farmer distributors. And they will share, you know, best practices risks, et cetera. And then they will bring those controls into, into, yeah.' (P7, male, distribution manager)

As found by Cho et al. (2015:281), Hoecht and Trott (2014:108) and Lima et al. (2018:123-124), firms develop visibility, collaborate with industry members, develop a risk management culture and share information with SC and industry members as resilience enablers to combat counterfeiting. However, firms in the South African pharmaceutical industry did not acknowledge flexibility, agility, sensing and redundancy as resilience enablers to combat counterfeiting as found by Lima et al. (2018:123-124).

\section{Conclusion}

\section{Discussion of the findings and managerial recommendations}

The aim of this study was to determine the sources of counterfeiting and the specific risk mitigation capabilities used to combat counterfeiting in the South African pharmaceutical industry. Further, this study aimed to determine the resilience enablers used to combat counterfeiting in the South African pharmaceutical industry. The first research question addressed the sources of counterfeiting for the South African pharmaceutical industry. This study confirms the findings of DiMase et al. (2016:1835-1836), Machado et al. (2018:157), Mohamed (2012:8) and Stevenson and Busby (2015:111-112), 
indicating that a source of counterfeiting is local manufacturing of counterfeited products, unauthorised distributors and imports of counterfeit products. The study expands on current literature by identifying sources of pharmaceutical counterfeiting related to outsourced manufacturing and distribution, diversion, non-reputable doctors or pharmacies and Internet sales, lack of accessibility to doctors and pharmacies and affordability of pharmaceutical products. Managers can consequently develop strategies to respond to the sources identified in this study. This can be performed by constantly monitoring their SC members and industry collaboration. This will enhance information sharing between all role players.

The second research question addressed the specific risk mitigation capabilities employed in the South African pharmaceutical industry. This study confirms the findings of Lima et al. (2018:121-122), indicating that by developing $R \& D$ strategies and internal structure firms can combat counterfeiting. Further, through strict government law and regulations, collaborating with industry members, creating partner strategies, constant monitoring of SC members, raising risk awareness, training members to identify counterfeits, strengthening their brand image, developing authentication technologies and traceability will enable them to effectively combat counterfeiting. However, this study found that there is a lack of use of data analytics solutions in the South African pharmaceutical industry to combat counterfeiting. Using data analytics in the pharmaceutical industry could increase the ability to analyse information generated by customers anywhere and can thus enable a firm to identify problems and take corrective actions. Moreover, this study contradicts the findings of Lima et al. (2018:121-122) by indicating that firms cannot increase or decrease their prices to combat counterfeiting. This is because the South African pharmaceutical industry is governed by the SEP, preventing manufacturers from increasing or decreasing the prices of products that need to be bought with a prescription. Changing the price for overthe-counter (OTC) products will have no effect as these products are extremely easy to come by and counterfeit. Managers can determine which of the mitigation capabilities they do not possess and develop these to combat counterfeiting.

The third research question addressed resilience enablers employed to combat counterfeiting. This study supports the findings of Lima et al. (2018:123-124), Hoecht and Trott (2014:108) and Cho et al. (2015:281) by indicating that firms develop visibility, collaborated with industry members, developing a risk management culture and shared information with SC and industry members. However, firms in the South African pharmaceutical industry did not acknowledge flexibility, agility, sensing and redundancy as resilience enablers to combat counterfeiting. Therefore, firms in the South African pharmaceutical industry may only have limited SCRES. Managers need to develop resilience enablers to combat counterfeiting. This can be performed through the implementation of redundancy to achieve flexibility and effectively combat counterfeiting. Increasing sensing in the pharmaceutical industry could increase the ability to analyse information generated by customers anywhere and can thus enable a firm to identify problems and take corrective actions.

\section{Limitations and directions for future research}

Because of the qualitative nature of the study, only 12 perspectives of the sources of counterfeiting, risk mitigation capabilities and resilience enablers to combat counterfeiting were obtained. Furthermore, the study did not measure which risk mitigation capabilities strengthen resilience enablers. Therefore, it would be valuable for future research to make use of a quantitative research design to include a larger sample and to effectively determine which risk mitigation capabilities strengthen resilience enablers to combat counterfeiting. Future studies can therefore investigate the nature of the relationships between these constructs.

In addition, limiting the study to one developing country limits the generalisability of its findings and transferability to other developing countries. Therefore, future research should be conducted in other developing countries to increase generalisability and to confirm the findings of other developing countries. The study did not determine which specific mitigation capabilities contribute most to effectively combatting counterfeiting. Future research should attempt to gain an in-depth understanding of which specific mitigation capabilities contribute most to effectively combatting counterfeiting. This can be performed by conducting case studies at firms that have been affected by counterfeiting and determining which capability contributed most to combatting counterfeiting.

\section{Acknowledgements Competing interests}

The authors declare that they have no financial or personal relationships that may have inappropriately influenced them in writing this article.

\section{Authors' contributions}

This article is based on the MPhil dissertation of C.T. who was the main researcher. W.N. acted as the supervisor with the conceptualisation, literature review, research instrument and development of this manuscript.

\section{Funding information}

This research received no specific grant from any funding agency in the public, commercial or not-for-profit sectors.

\section{Data availability}

Data are stored according to institutional policy.

\section{Disclaimer}

The views and opinions expressed in this article are those of the authors and do not necessarily reflect the official policy or position of any affiliated agency of the author. 


\section{References}

Ambulkar, S., Blackhurst, J.V. \& Cantor, D.E., 2016, 'Supply chain risk mitigation competency: An individual-level knowledge-based perspective', International Journal of Production Research 54(5), 1398-1411. https://doi.org/10.1080/00207 543.2015.1070972

Antonie, F., Simkins, C., Van Dalsen, A., Chetty, K., Collocott, C., Toxopeus, M. et al., 2018, The supply of pharmaceuticals in South Africa, viewed 02 May 2019, from https://hsf.org.za/publications/special-publications/pharmaceuticals-insouthafrica/pharma-report-2018.pdf.

Blackhurst, J., Dunn, K.S. \& Craighead, C.W., 2011, 'An empirically derived framework of global supply resiliency', Journal of Business Logistics 32(4), 374-391. https:// doi.org/10.1111/j.0000-0000.2011.01032.x

Braun, V. \& Clarke, V., 2006, 'Using thematic analysis in psychology', Qualitative Research in Psychology 3, 77-101.

Cesareo, L. \& Stöttinger, B., 2015, 'United we stand, divided we fall: How firms can engage consumers in their fight against counterfeits', Business Horizons 58(5), 527-537. https://doi.org/10.1016/j.bushor.2015.05.007

Chaudhry, P.E. \& Stumpf, S.A., 2013, 'The challenge of curbing counterfeit prescription drug growth: Preventing the perfect storm', Business Horizons 56(2), 189-197. drug growth: Preventing the perfect storm',
https://doi.org/10.1016/j.bushor.2012.11.003

Cho, S.H., Fang, X. \& Tayur, S., 2015, 'Combating strategic counterfeiters in licit and illicit supply chains', Manufacturing \& Service Operations Management 17(3), 273-289. https://doi.org/10.1287/msom.2015.0524

Chowles, T., 2017, 'How medicine prices are regulated in South Africa', eHealth News, viewed 04 September 2019, from https://ehealthnews.co.za/medicine-pricesregulated-south-africa/.

Chowdhury, M.M.H. \& Quaddus, M., 2016, 'Supply chain readiness, response and recovery for resilience', Supply Chain Management 21(6), 709-731. https://doi. org/10.1108/SCM-12-2015-0463

Christopher, M., 2016, Logistics \& supply chain management, 5th edn., Pearson Education, Úpper Saddle River, NJ.

Christopher, M. \& Peck, H., 2004, 'Building the resilient supply chain', The Internationa Journal of Logistics Management 15(2), 1-14. https://doi.org/10.1108/0957409 0410700275

Coustasse, A., Arvidson, C. \& Rutsohn, P., 2010, 'Pharmaceutical counterfeiting and the RFID technology intervention', Journal of Hospital Marketing \& Public Relations 20(2), 100-115. https://doi.org/10.1080/15390942.2010.493369

Craighead, C.W., Blackhurst, J., Rungtusanatham, M.J. \& Handfield, R.B., 2007, 'The severity of supply chain disruptions: Design characteristics and mitigation capabilities', Decision Sciences 38(1), 131-156. https://doi.org/10.1111/j.1540capabilities', Decision
5915.2007.00151.x

Creswell, J.W., 2012, Educational research: Planning, conducting, and evaluating quantitative and qualitative research, 4th edn., Pearson, Boston, MA.

Dégardin, K., Roggo, Y. \& Margot, P., 2014, 'Understanding and fighting the medicine counterfeit market', Journal of Pharmaceutical and Biomedical Analysis 87(1), 167-175. https://doi.org/10.1016/j.jpba.2013.01.009

Dekker, H.C., Sakaguchi, J. \& Kawai, T., 2013, 'Beyond the contract: Managing risk in supply chain relations', Management Accounting Research 24(2), 122-139. https://doi.org/10.1016/j.mar.2013.04.010

DiMase, D., Collier, Z.A., Carlson, J., Gray Jr, R.B. \& Linkov, I., 2016, 'Traceability and risk analysis strategies for addressing counterfeit electronics in supply chains for complex systems', Risk Analysis 36(10), 1834-1843. https://doi.org/10.1111/ risa.12536

DuHadway, S., Carnovale, S. \& Hazen, B., 2019, ‘Understanding risk management for intentional supply chain disruptions: Risk detection, risk mitigation, and risk recovery', Annals of Operations Research 283(1), 179-198. https://doi. org/10.1007/s10479-017-2452-0

Ehrenhuber, I., Treiblmaier, H., Engelhardt-Nowitzki, C. \& Gerschberger, M., 2015 'Toward a framework for supply chain resilience', International Journal of Supply Chain and Operations Resilience 1(4), 1-12. https://doi.org/10.1504/IJSCOR. 2015.075084

Enyinda, C.I. \& Tolliver, D., 2009, 'Taking counterfeits out of the pharmaceutical supply chain in Nigeria: Leveraging multilayer mitigation approach', Journal of African Business 10(2), 218-234. https://doi.org/10.1080/15228910903 187957

Fiksel, J., Polyviou, M., Croxton, K. \& Pettit, T., 2015, 'From risk to resilience: Learning to deal with disruption', MIT Sloan Management Review 56(2), 79-86.

Green, R.T. \& Smith, T., 2002, 'Executive insights: Countering brand counterfeiters', Journal of International Marketing 10(4), 89-106. https://doi.org/10.1509/ jimk.10.4.89.19551

Guest, G., Bunce, A. \& Johnson, L., 2006, 'How many interviews are enough? An experiment with data saturation and variability', Field Methods 18(1), 59-82. https://doi.org/10.1177/1525822X05279903

Hoecht, A. \& Trott, P., 2014, 'How should firms deal with counterfeiting? A review of the success conditions of anti-counterfeiting strategies', International Journal of Emerging Markets 9(1), 98-119. https://doi.org/10.1108/IJOEM-02Journal of Eme

Hohenstein, N.-O., Feisel, E., Hartmann, E. \& Giunipero, L., 2015, 'Research on the phenomenon of supply chain resilience: A systematic review and path for further investigation', International Journal of Physical Distribution \& Logistics Management 45(1/2), 90-117. https://doi.org/10.1108/IJPDLM-052013-0128
Jüttner, U. \& Maklan, S., 2011, 'Supply chain resilience in the global financial crisis: An empirical study', Supply Chain Management: An International Journal 16(4), 246-259. https://doi.org/10.1108/13598541111139062

Jüttner, U., Peck, H. \& Christopher, M., 2003, 'Supply chain risk management: Outlining an agenda for future research', International Journal of Logistics: Research and Applications 6(4), 197-210. https://doi.org/10.1080/1367556031 0001627016

Kamalahmadi, M. \& Parast, M.M., 2016, 'A review of the literature on the principles of enterprise and supply chain resilience: Major findings and directions for future research', International Journal of Production Economics 171(1), 116-133. https:// doi.org/10.1016/j.ijpe.2015.10.023

Koffi, C., 2018, 'Fake medicines on the rise despite killing thousands in Africa', IOL, viewed 01 May 2019, from https://www.iol.co.za/news/africa/fake-medicineson-the-rise-despite-killing-thousands-in-africa-12763206.

Krebs, M., 2018, 'The South African pharmaceutical regulatory environment', Engineering News, viewed 08 October 2019, from http://www.engineeringnews. co.za/article/the-south-african-pharmaceutical-regulatory-environment-201806-20/rep_id:4136.

Kumar, S., Dieveney, E. \& Dieveney, A., 2009, 'Reverse logistic process control measures for the pharmaceutical industry supply chain', International Journal of Productivity and Performance Management 58(2), 188-204. https://doi.org/ 10.1108/17410400910928761

Kwok, S.K., Ting, S.L., Tsang, A.H. \& Cheung, C.F., 2010, 'A counterfeit network analyzer based on RFID and EPC', Industrial Management \& Data Systems 110(7) 1018-1037. https://doi.org/10.1108/02635571011069086

Li, F. \& Yi, Z., 2017, 'Counterfeiting and piracy in supply chain management: Theoretical studies', Journal of Business \& Industrial Marketing 32(1), 98-108. https://doi. org/10.1108/JBIM-09-2015-0171

Li, L., 2013, 'Technology designed to combat fakes in the global supply chain', Business Horizons 56(2), 167-177. https://doi.org/10.1016/j.bushor.2012.11.010

Lima, F.R.P.D., Da Silva, A.L., Godinho Filho, M. \& Dias, E.M., 2018, 'Systematic review: Resilience enablers to combat counterfeit medicines', Supply Chain Management: An International Journal 12(3), 117-135. https://doi.org/10.1108/ Management: An Inter

Lybecker, K.M., 2008, 'Keeping it real: Anti-counterfeiting strategies in the pharmaceutical industry', Managerial and Decision Economics 29(5), 389-405. https://doi.org/10.1002/mde.1405

Machado, S.M., Paiva, E.L. \& Da Silva, E.M., 2018, 'Counterfeiting: Addressing mitigation and resilience in supply chains', International Journal of Physical Distribution \& Logistics Management 48(2), 139-163. https://doi.org/10.1108/ IJPDLM-01-2017-0004

Meraviglia, L., 2015, 'Counterfeiting, fashion and the civil society', Journal of Fashion Marketing and Management 19(3), 230-248. https://doi.org/10.1108/JFMM-062013-0084

Merriam, S.B., 2009, 'Qualitative case study research', in Qualitative Research: A Guide to Design and Implementation 4th Edition, by Sharan B. Merriam, Elizabeth J. Tisdell, San Francisco, CA : Jossey-Bass : A Wiley Brand, pp. 39-54.

Milne, J. \& Oberle, K., 2005, 'Enhancing rigor in qualitative description', Journal of Wound, Ostomy and Continence Nursing 32(6), 413-420. https://doi. org/10.1097/00152192-200511000-00014

Mohamed, K., 2012, 'Trademark counterfeiting: Comparative legal analysis on enforcement within Malaysia and the United Kingdom and at their borders', PhD thesis, Newcastle University.

Naderpajouh, N., Hastak, M., Gokhale, S., Bayraktar, M.E., Iyer, A. \& Arif, F., 2015 'Counterfeiting risk governance in the capital projects supply chain', Journal of Construction Engineering and Management 141(3), 1-11. https://doi. org/10.1061/(ASCE)CO.1943-7862.0000943

Papadopoulos, T., Gunasekaran, A., Dubey, R., Altay, N., Childe, S.J. \& Fosso-Wamba, S., 2017, 'The role of Big Data in explaining disaster resilience in supply chains for sustainability', Journal of Cleaner Production 142(1), 1108-1118. https://doi. org/10.1016/j.j.jepro.2016.03.059

Pettit, T.J., Croxton, K.L. \& Fiksel, J., 2013, 'Ensuring supply chain resilience: Development and implementation of an assessment tool', Journal of Business Logistics 34(1), 46-76. https://doi.org/10.1111/jbl.12009

Plano-Clark, V.L. \& Creswell, J.W., 2014, Understanding research: A consumer's guide, Pearson, Boston, MA.

Polit, D.F. \& Beck, C.T., 2012, Nursing research: Generating and assessing evidence for nursing practice, 9th edn., Wolters Kluwer Health | Lippincott Williams \& Wilkins, Philadelphia, PA.

Ponomarov, S.Y. \& Holcomb, M.C., 2009, 'Understanding the concept of supply chain resilience', The International Journal of Logistics Management 20(1), 124-143. https://doi.org/10.1108/09574090910954873

Quinlan, C., Babin, B., Carr, J., Griffin, M. \& Zikmund, W.G., 2015, Business research methods, Cengage Learning, Hampshire.

Rashid, A.H.M., Loke, S.-P. \& Ooi, K.-B., 2014, 'Strengthening supply chain risk management for business continuity: A case study approach', International Journal of Management and Enterprise Development 13(3-4), 278-301. https:// doi.org/10.1504/IJMED.2014.069173

Renschler, J.P., Walters, K.M., Newton, P.N. \& Laxminarayan, R., 2015, 'Estimated under-five deaths associated with poor-quality anti-malarials in sub-Saharan Africa', The American Journal of Tropical Medicine and Hygiene 92(6), 119-126. https://doi.org/10.4269/ajtmh.14-0725

Rowley, J., 2012., 'Conducting research interviews', Management Research Review 35(3/4), 260-271. https://doi.org/10.1108/01409171211210154 
Scholten, K., Scott, S.P. \& Fynes, B., 2014, 'Mitigation processes-antecedents for building supply chain resilience', Supply Chain Management: An International Journal 19(2), 211-228. https://doi.org/10.1108/SCM-06-2013-0191

Sheffi, Y. \& Rice, Jr., J.B., 2005, 'A supply chain view of the resilient enterprise', MIT Sloan Management Review 47(1), 41-49. https://doi.org/10.1111/j.1055-6001. 2005.04103005.x

Shenton, A.K., 2004, 'Strategies for ensuring trustworthiness in qualitative research projects', Education for Information 22(2), 63-75.

Soni, U., Jain, V., Sánchez, S. \& Paz, M., 2015, 'Coping with uncertainties via resilient supply chain framework', International Journal of Procurement Management 1(1), 182-201. https://doi.org/10.1504/IJPM.2015.066294

Speier, C., Whipple, J.M., Closs, D.J. \& Voss, M.D., 2011, 'Global supply chain design considerations: Mitigating product safety and security risks', Journal of Operation Management 29(7-8), 721-736. https://doi.org/10.1016/j.jom.2011.06.003

Stevenson, M. \& Busby, J., 2015, 'An exploratory analysis of counterfeiting strategies: Towards counterfeit-resilient supply chains', International Journal of Operations \& Production Management 35(1), 110-144. https://doi.org/10.1108/IJOPM-042012-0174

Stumpf, S.A. \& Chaudhry, P., 2010, 'Country matters: Executives weigh in on the cause and counter measures of counterfeit trade', Business Horizons 53(3), 305-314. https://doi.org/10.1016/j.bushor.2010.01.004
Taylor, D., 2014, 'RFID in the pharmaceutical industry: Addressing counterfeits with technology', Journal of Medical Systems 38(11), 129-141. https://doi.org/ 10.1007/s10916-014-0141-y

Thenga, G., 2018, 'A critical analysis of the policing of counterfeit goods in South Africa', thesis, University of South Africa.

Tukamuhabwa, B.R., Stevenson, M., Busby, J. \& Zorzini, M., 2015, 'Supply chain resilience: Definition, review and theoretical foundations for further study', International Journal of Production Research 53(18), 5592-5623. https://doi.org/ 10.1080/00207543.2015.1037934

Urciuoli, L., 2010, 'Supply chain security - Mitigation measures and a logistics multilayered framework', Journal of Transportation Security 3(1), 1-28. https://doi. org/10.1007/s12198-009-0034-3

Von Holdt, B., 2017, Counterfeit medicines: Local health treat? viewed 28 April 2019, from https://www.mm3admin.co.za/documents/docmanager/2d5ed792-878c4371-9575-8281a96bbb26/00015857.pdf.

Walsh, J., 2019, 'Tackling the scourge of counterfeit drugs in Africa', Bizcommunity viewed 01 April 2019, from https://www.bizcommunity.com/Article/196/398/ 186896.html.

Wilson, J.M., Grammich, C. \& Chan, F., 2016, 'Organizing for brand protection and responding to product counterfeit risk: An analysis of global firms', Journal of Brand Management 23(3), 345-361. https://doi.org/10.1057/bm.2016.12 